\title{
Developing a Practical Framework for ERP Project Implementation: A Proposed Research Design
}

\author{
John J. Sullivan, Mela Wyeth, and Wade M. Chumney \\ Charleston Southern University, School of Business and Economics \\ Charleston, South \\ Carolina, 29423 USA \\ \{jsullivan, mwyeth, wchumney\}@csuniv.edu
}

\begin{abstract}
The implementation of Enterprise Resource Planning (ERP) systems is famous for mismanagement, unfulfilled expectations, and even outright failure. While some organizations undertaking this effort manage to report on-time schedules, intact budgets, and systems capable of providing measurable value to the organization, this is the exception rather than the rule. The objective of this research project is to focus on organizational reliability. This paper will delineate a proposed research design that will enable one to quantify the impact of organizational factors on ERP projects. Those factors will be classified in five broad categories: risk factors, expectations, resources, organizational competence, and consequences. The benefit of this research will be threefold: 1) to assess organizational readiness for undertaking an ERP project, 2) to identify areas of weakness within an organization, and 3) to predict with confidence the outcome of the ERP project in terms of common project metrics (budget, schedule, system capability, etc.). In practice, this would enable ERP project managers to possess a comprehensive understanding of project vulnerability and allow them to strengthen areas of weakness prior to project implementation.
\end{abstract}

\section{Introduction}

The worst kept secret in IS might be that management of complex systems such as ERP systems possesses enormous potential for mismanagement, unfulfilled expectations, and outright failure.

Please use the following format when citing this chapter:

Sullivan, J., J., Wycth, M., Chumney, W., M., 2006, in International Federation for Information Processing, Volume 205, Research and Practical Issues of Enterprise Information Systems, cds. Tjoa, A.M., Xu, L., Chaudhry, S., (Boston:Springer), pp.341-351. 
While some organizations manage to report on-time schedules, intact budgets, and systems capable of providing measurable value to the organization, those that fall woefully short are much more prevalent. Researchers [1] have identified many real world examples of ERP projects that have experienced difficulty. Those difficulties can cause significant problems for the companies that depend on them.

This research project will focus on organizational reliability. Sullivan and Beach's [2] model of how High Reliability Organizations (HROs) manage complex systems, provides a novel method of representing the dynamics of managing complex systems, sometimes in hazardous environments. Factors that impact these projects can be categorized into five broad categories: risk factors, expectations, resources, organizational competence, and consequences. Using HROs as an example of a consistently effective management environment, and overlaying critical success factors for ERP implementations found in the literature, a representation of an effective ERP implementation is proposed. Conversely, it is expected that this same method can be applied to represent ineffective ERP implementation.

The objective of this paper is to outline a proposed research design that will lead to the ability to quantify the impact of organizational factors on ERP projects. Ultimately, an analysis of a significant volume of statistical data regarding the outcomes of ERP projects and the impact of particular factors on project performance will be required.

The benefits of this research for practitioners will be the ability to assess organizational readiness for undertaking an ERP project, identify areas of weakness, and predict with a degree of confidence the outcome of the project in terms of common project metrics such as budget, schedule, and system capability. This would enable ERP project managers to better understand project vulnerability and strengthen areas of weakness prior to project implementation.

\section{ERP Systems and Outcomes}

ERP systems are comprehensive packages of software solutions that integrate all business processes and organizational functions to define a holistic view of the business from a single information architecture [3]. These systems are comprised of customizable, standard application software modules that integrate business solutions for core business processes and administrative functions [4].

Further, they provide comprehensive integrated business functionality using a state-of-the-art IT infrastructure [5] that can improve the information flow within organizations significantly [6]. In addition, they also provide the capability to improve core business practices, such as human resources, manufacturing, marketing, and finance. This is accomplished by standardizing business functions based on best business practices $[7,8]$

ERP implementations require skillful management. In summarizing the recommendations of other researchers as to how ERP implementations should be managed, a list of critical success factors has been compiled. Table 1 reflects the general categories of those factors and the authors who provided the findings. 
Included in the table are critical success factors identified by SAP [9], a vendor of ERP systems.

Table 1. Critical Success Factors for ERP Implementations by Author

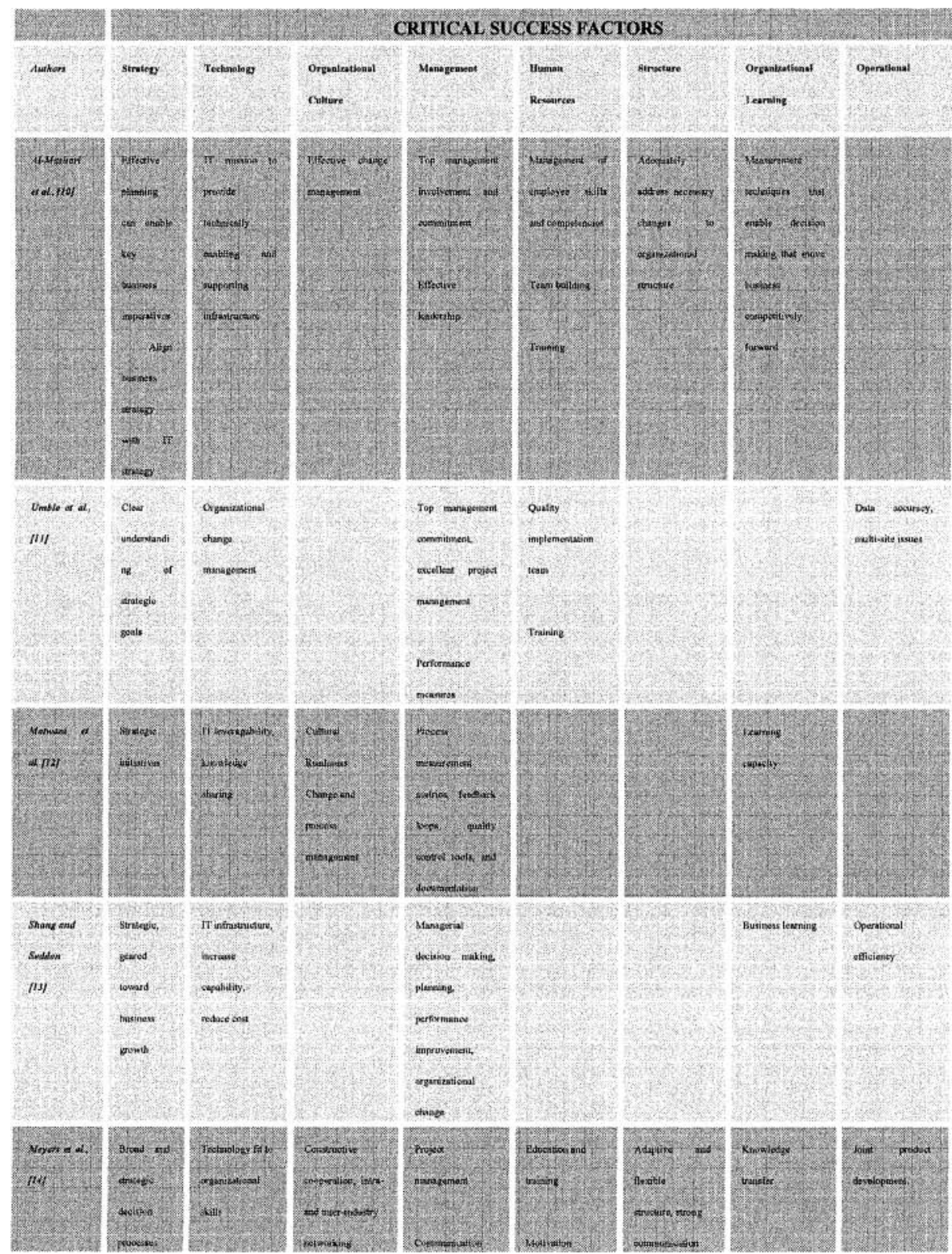




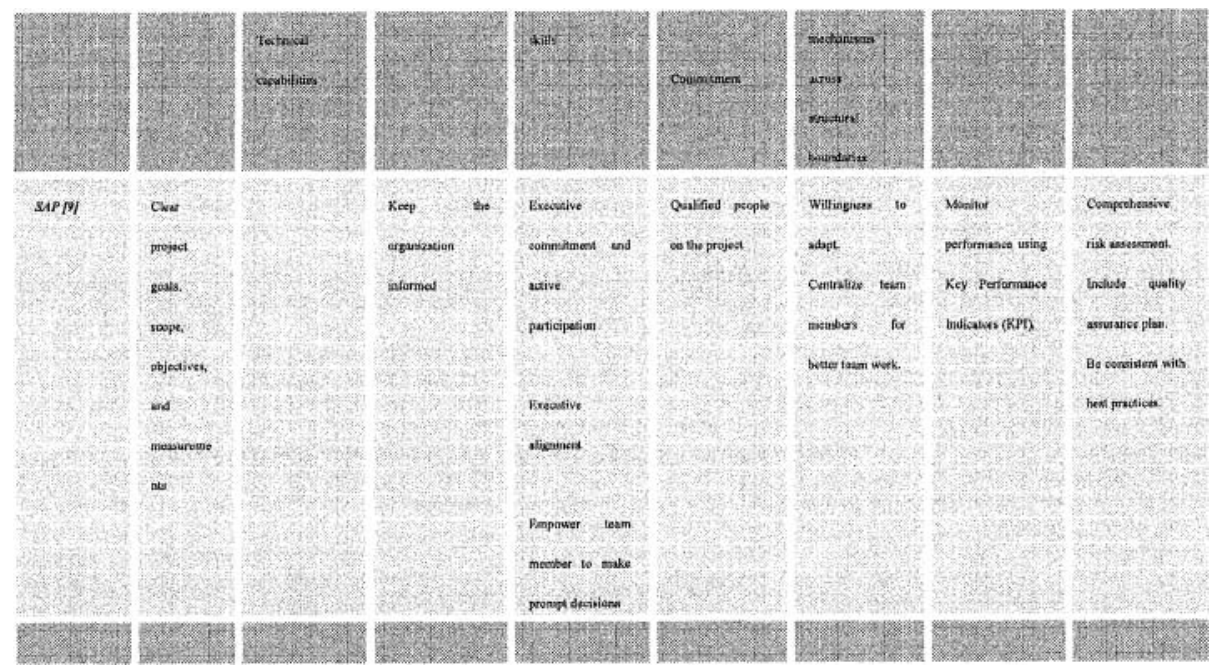

Despite the recommendations of how ERP projects should be managed, failure among ERP implementations has been widely documented [7, 15, 16, and 11]. Langenwalter [17] reported that ERP implementation failures range from 40 percent to over 60 percent, while Ptak [18] suggests that ERP systems that failed to provide the expected Return on Investment (ROI) are as high as 60-90 percent. These statistics are comparable to the Standish Group's [19] findings where they reported that as much as 83 percent of all IS/IT projects encounter some significant difficulty or failure. Clearly, success rates for ERP outcomes are consistent with historical patterns of IS/IT project performance. Thus, while not all ERP implementations are failures, the problem is still chronic.

The impact of an ERP implementation failure can be significant, since the cost of these systems is often in the hundreds of millions of dollars. In extreme cases, it can even threaten the financial viability of the organization.

\section{Characteristics of HROs}

The above withstanding, Roberts and Bea [20] suggest that some organizations have been very successful in their implementation of complex systems (e.g., those controlling nuclear power stations and chemical processes.). These organizations, by the very nature of what they do require a high degree of reliability from their systems, procedures, and people.

HROs operate in an environment where the tolerances for error are extremely slim. Roberts [21] identifies what it means to be a HRO by posing the question, "How often could this organization have failed with dramatic consequences?" If failure could have occurred many thousands of times, the organization is highly reliable. Another characteristic of HROs is that, "performance reliability rivals productivity as a dominant goal" [21]. 
Sullivan and Beach [2] suggest that it is the ability to balance capability and risk in the face of high consequence that separate HROs from traditionally less critical organizations. The Sullivan-Beach Model (Figure 1) provides an illustration of the dynamics of managing complex systems in HROs using a scale to represent the weight of risk and the required weight of capability to counteract that risk.

Failure occurs when risk, comprised of expectations and risk factors, outweighs an organization's capability, comprised of resources and organizational competence. In such cases the scale tips out of balance, and consequences follow.

Bilateral relationships in this model exist between expectations and consequences, as well as expectations and resources. Additionally, a one-way relationship between consequences and organizational competence exists. Expectations and consequences are related in that the consequences for failure are consistent with the degree of missed expectations. For example, a delay in

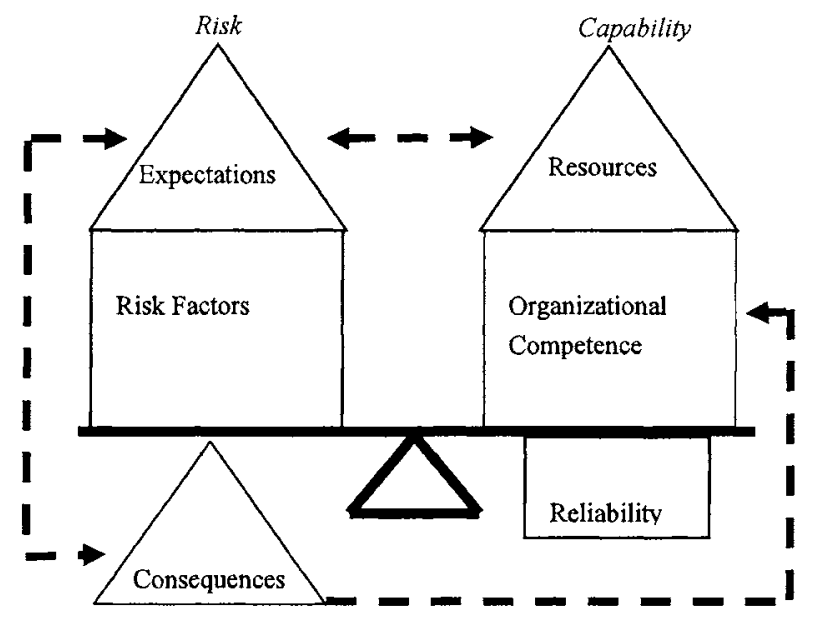

Fig. 1. Conceptual Model for How HROs Manage Complex Systems

launching the space shuttle by one day violates an expectation that the shuttle program stay on schedule. However, the consequences of failing to meet this expectation are minor. Higher order expectations include returning the shuttle and its crew safely to earth. Failing to meet those expectations involves severe consequences [2].

The relationship between expectations and resources is demonstrated when stakeholders (government agencies, for example) provide resources to a project. Certain expectations, or a return on investment, accompany those resource commitments. Conversely, if resources are withdrawn, project managers will insist that stakeholders lower their expectations, or failure will result. Similarly, if expectations increase, managers will demand additional resources [2].

Finally, the one-way relationship between consequences and organizational competence is best described as organizational learning. When HROs fail, an investigation follows, and what is learned contributes to changes in policies and 
procedures that increase organizational competence so that a particular type of failure does not occur again [2].

\section{Commonalities between HROs and ERP Systems}

ERP systems have become the norm for medium to large companies. Thus, there is a real need to improve the likelihood of ERP implementation success. Based on the Sullivan-Beach Model, HROs share considerable commonality with ERP implementations:

- complex, highly integrated, systems,

- significant resource investment,

- high expectations for success,

- risk factors that threaten success,

- significant consequences for failure (i.e., punitive, financial, etc.),

ERP and HRO systems have similar factors that influence their success. System complexity, resource commitments, high expectations, and risk all interrelate in the environment of these systems.

\section{Research Design}

The environment of IS project management is complex, with a broad range of interacting variables. The proliferation of ERP systems requires a study into the factors that influence the success of these complex projects in order to both identify areas for potential failure, and quantify their impact. This will provide a method of evaluating organizational readiness and forecasting project performance in advance. Obvious benefits to organizations include identifying weakness and risks that threaten the success of the initiative, and mitigating them before they impact the project.

From these observations, questions arise that will require further empirical study. "Can a correlation between success factors and impact on project performance be reliably quantified?"

"How can factors of organizational readiness for an ERP implementation be quantified and used to predict project performance?"

Effectively studying a topic this complex will be difficult if only a single measurement tool were to be used. This research design will propose using a combination of methods that will approach the data from multiple perspectives, each designed to provide a specific insight into the topic. This framework will incorporate a combination, or triangulation, of qualitative and quantitative methods.

Researchers [22, 23] have consistently noted the benefits of triangulation. Frankfort-Nachmias and Nachmias [24] define triangulation as the "use of more than one form of data collection to test the same hypothesis within a unified research 
plan". The author further adds, "To minimize the degree of specificity of certain methods to particular bodies of knowledge, a researcher can use two or more methods of data collection to test hypotheses and measure variables; this is the essence of triangulation" [24]. A summary of this research design is provided in Table 2.

Table 2. Research Design Summary

\begin{tabular}{|c|c|c|c|c|c|}
\hline & Research & Scope & & & \\
\hline Phase & Depth & Breduth & $\begin{array}{c}\text { Source of } \\
\text { Data }\end{array}$ & $\begin{array}{l}\text { Type of } \\
\text { Analysis }\end{array}$ & Purpose of Analysis \\
\hline 1 & Low & $\begin{array}{l}\text { Very } \\
\text { High }\end{array}$ & $\begin{array}{l}\text { Published } \\
\text { Literature }\end{array}$ & $\begin{array}{l}\text { Literature } \\
\text { Review }\end{array}$ & $\begin{array}{l}\text { Exploratory: Identification of scope of } \\
\text { system development failures, historical } \\
\text { practices, relevant issues, and success } \\
\text { factors. }\end{array}$ \\
\hline 2 & High & Low & Interview & $\begin{array}{l}\text { Analysis } \\
\text { across } \\
\text { organizations }\end{array}$ & $\begin{array}{l}\text { Theory formulation: Identification of } \\
\text { relevant forces (technical, managerial, } \\
\text { procedural and organizational culture) } \\
\text { affecting project outcomes. }\end{array}$ \\
\hline & & & & & Identify success strategy effectiveness. \\
\hline & & & & & $\begin{array}{l}\text { Identification of deviation points of system } \\
\text { development planning that invite failure. }\end{array}$ \\
\hline & & & & & $\begin{array}{l}\text { Compare and contrast HRO and } \\
\text { commercial ERP development } \\
\text { environment. }\end{array}$ \\
\hline 3 & Medinn & High & $\begin{array}{l}\text { Survey } \\
\text { Data }\end{array}$ & $\begin{array}{l}\text { Statistical } \\
\text { Analysis }\end{array}$ & $\begin{array}{l}\text { Confirmation Validation of theoretical } \\
\text { constructs over larger population. }\end{array}$ \\
\hline 4 & $\begin{array}{l}\text { Very } \\
\text { High }\end{array}$ & $\begin{array}{l}\text { Very } \\
\text { Low }\end{array}$ & $\begin{array}{l}\text { Practical } \\
\text { Application }\end{array}$ & $\begin{array}{l}\text { Evaluation } \\
\text { feedback }\end{array}$ & $\begin{array}{l}\text { Test and Evaluation: Validate ERP factor } \\
\text { valuation framework through application } \\
\text { in practice. }\end{array}$ \\
\hline
\end{tabular}

\section{$5.1 \quad$ Literature Review}

This research began with a review of published literature in order to establish relevant issues and relationships that influence system development in general, as well as that of HRO and ERP systems. This review supported the findings of Sullivan and Beach [2] and the developmental model they posited. Consequently, 
we will use this model as a basis to proceed. This process establishes a theoretical underpinning for the remainder of the research.

\subsection{Qualitative Exploratory Phase}

The interview process will provide a method of extracting the experiences and observations of the participants involved in developing these systems. While interviews provide limited breadth, they allow a high degree of depth and detail into this area of research. This process will involve a small number of participants, approximately twenty interviewees. Interview data will be processed in order to identify the major issues that affect system development outcomes. The information gleaned in this exploratory phase will form the basis of the instrument created in the confirmatory phase.

\subsection{Quantitative Confirmatory Phase}

Once the major issues are identified, a survey instrument will provide a method of validating the existence and influence of these issues over a larger population of participants. A statistical analysis of responses will allow correlations to be drawn between success factors and ERP project performance metrics.

\subsection{Practical Application}

The practical applications of this research are significant. The objective is to obtain the ability to predict project performance in advance of the project so that weaknesses can be identified and corrected before they impact the project. The ability to make a correlation between factors that contribute to success and failure of ERP projects with a quantifiable impact on project metrics will be valuable to ERP vendors, consultants, and their clients. As the impact of these factors becomes known, it is expected that an assessment of organizational readiness could provide an estimate of budget and schedule overruns. It is hoped that the resulting framework will enable an environment of trial without error.

The obvious benefit of having the capability to estimate project performance before it begins is that corrections can be made to organizational weaknesses before they impact the project. Further refinement of this knowledge over time can lead to contributions in other areas of system development as well.

\section{Development of a Practical Framework}

\subsection{Training}

Organizations that seek to develop success-oriented professionals to participate in ERP projects could emphasize the importance of effective project management using examples from this research. Training programs provide an opportunity to instill not 
only effective management practices, but organizational philosophy and culture. Organizations could understand how projects result in failure and what each factor costs.

\subsection{ERP System Managers}

As a practical solution to improve the long history of failure with ERP systems, managers might realize organizational benefits where in the past they experienced difficulties. Project personnel could be held accountable for project performance, since they would have advanced notice of risk factors and organizational weaknesses in advance of the project. One lessen learned in HROs is that accountability tends to drive higher levels of performance.

\subsection{ERP Vendors and Consultants}

By incorporating techniques developed in this research project, ERP vendors and consultants will enhance their credibility with clients. As the findings from this research are refined over time, it will reinforce the correlation between project factors and the impact on project metrics.

\section{Conclusions}

ERP systems have a high potential for mismanagement, unfulfilled expectations, and failure. While some organizations manage to get it right, many fall short. Researchers have written much about success factors and techniques for improving project outcomes, yet millions of dollars are lost to inefficiency and ineffectiveness in managing ERP projects.

Using Sullivan and Beach's [2] model representing the dynamics of how HROs manage complex systems, the objective of this research project is ultimately to put a price tag in misalignment with established success factors for ERP projects. To accomplish this, interviews will be used to perform the exploratory data collection and identify major themes in this area. Then, survey questionnaires will provide quantitative data over a larger population. Statistical analysis will establish the degree of correlation between project factors and project performance metrics.

The benefits of this research for practitioners will be the ability to assess organizational readiness for undertaking an ERP project, identify areas of weakness, and predict with a degree of confidence the outcome of the project in terms of common project metrics such as budget, schedule, and system capability.

The industry benefits resulting from an effective framework for system development based on the experiences of HROs would likely include:

- Understanding the origins of factors that lead to comprehensive system failure.

- Learning how theoretically harmless anomalies can develop into significant threats. 
- Learning to proactively identify and correct adverse symptoms early in the project rather than reacting to their future effects.

- Developing project management techniques that prevent the emergence of these project threats.

- Understanding the effects of organizational culture on individuals' motivations concerning his/her responsibilities to the organization.

With the proliferation of vastly complex ERP systems, organizations need to be aware that failing to follow effective system development practices can result in mortal financial injury for even the most affluent corporations. The ERP development industry has strongly suggested that organizations be open to modifying the way they do business in order to align themselves with industry best practices.

\section{References}

1. C. Soh, S. Tien, J. Tay-Yap, Cultural Fits and Misfits: Is ERP a Universal Solution? Communications of the ACM, 43(4), 47-51 (2000).

2. J. Sullivan, R. Beach, In Hunter, M. Gordon, and Kathy Dhanda (eds.). Information Systems: Exploring Applications in Business and Government, The Information Institute, Las Vegas, Nevada. USA (2004).

3. G. Gable, Large Package Software: A Neglected Technology, Journal of Global Information Management 6( 3), 3-4 (1998).

4. M. Rosemann, ERP-Software-Characteristics and Consequences, Proceedings of the $7^{\text {th }}$ European Conference on Information Systems, 1999-ECIS'99, Copenhagen, DK (1999).

5. E. Watson, M. Rosemann, G. Stewart, An Overview of Teaching and Research using SAP $\mathrm{R} / 3$, Proceedings from the Americas Conference on Information Systems (AMCIS) 1999 Conference (1999).

6. T. Davenport, Putting the Enterprise into the Enterprise System, Harvard Business Review, 121-131 (1998).

7. N. Bancroft, H. Seip, and A. Sprengel, Implementing SAP R/3: How to Introduce a Large System into a Large Organization, (Greenwich, Connecticut: Manning Publication Company, 1998).

8. C. Holland, B. Light, A Critical Success Factors Model for ERP Implementation, IEEE Software May/June, 30-35(1999).

9. SAP in K-12, Presentation to K-12 School District (anonymous) for Planning SAP Implementation (2004).

10. M. Al-Mashari, A. Al-Mudimigh, and M. Zairi, Enterprise Resource Planning: A Taxonomy of Critical Factors, European Journal of Operational Research 146, pp. 352-364 (2003).

11. E. Umble, R. Haft, and M. Umble, Enterprise Resource Planning: Implementation Procedures and Critical Success Factors, European Journal of Operations Research 146, 241257 (2003).

12. J. Motwani, D. Mirchandani, M. Madan, and A. Gunasekaran, Successful Implementation of ERP Projects: Evidence from Two Case Studies, International Journal of Production Economics 75, 83-96 (2002). 
13. S. Shang and P. Seddon, A Comprehensive Framework for Classifying the Benefits of ERP Systems, Proceedings of the Americas Conference on Information Systems (AMCIS 2000), Volume 2: pp. 1005-1014 (2000).

14. P.W. Meyers, K. Sivakumar, and C. Nakata, Implementations of Industrial Process Innovations: Factors, Effects, and Marketing, Journal of Product Innovation Management 16, 295-311(1999).

15. D. Cooke and W. Peterson, SAP Implementation: Strategies and Results, Research Report 1217-98-RR, New York: The Conference Board (1998).

16. S.P. Laughlin, An ERP Game Plan, Journal of Business Strategy 20(1), 32, (1999).

17. G. Langenwalter, Enterprise Resource Planning and Beyond: Integrating Your Entire Organization (Boca Raton, Florida: St. Lucie Press, 2000).

18. C. Ptak, ERP Implementation: Surefire Steps to Success, Proceedings from the ERP World Conference 1999.

19. Standish Group The CHAOS Report, The Standish Group Web Site: http://www.standishgroup.com/chaos.html (1994).

20. K. Roberts and R. Bea, Must Accidents Happen? Lessons from High Reliability Organizations, Academy of Management Executive 15(3) (2001a).

21. K. Roberts, "Managing High Reliability Organizations," Organization, Summer 1990 (1990a).

22. N.K. Denzin, The Research Act in Sociology (Aldine, Chicago, 1970).

23. R. Yin, Case Study Research Design and Methods, (Third Edition. Thousand Oaks, California: SAGE Publications, 2003).

24. C. Frankfort-Nachmias and D. Nachmias, Research Methods in Social Sciences, (Fifth Edition, New York: St. Martin's Press, 1996). 